\title{
Constructivist Evaluation of a Stage-Based Decision Support Intervention Re- garding Dialysis Modality Choice
}

\author{
Marie-Chantal Loiselle ${ }^{1, *}$, Annette M O'Connor ${ }^{2}$, and Cécile Michaud ${ }^{1}$ \\ ${ }^{1}$ School of Nursing Sciences, Faculty of Medicine and Health Sciences, University of Sherbrooke, Longueuil, Canada \\ ${ }^{2}$ Faculty of Health Sciences, University of Ottawa, Ottawa, Canada
}

\begin{abstract}
*Corresponding author: Marie-Chantal Loiselle, Assistant Professor, School of Nursing Sciences, Faculty of Medicine and Health Sciences, University of Sherbrooke, 150, Place Charles-Le Moyne, Bureau 200, Longueuil (QC) J4K 0A8, Canada, Phone: 450-463-1835 ext 61790; E-mail: marie-chantal.loiselle@usherbrooke.ca
\end{abstract}

Received: 30 Apr, 2021 | Accepted: 23 Jun, 2021 | Published: 30 Jun, 2021

Citation: Loiselle MC, O'Connor AM, Michaud C (2021) Constructivist Evaluation of a Stage-Based Decision Support Intervention Regarding Dialysis Modality Choice. Int J Nephrol Kidney Fail 7(2): dx.doi.org/10.16966/2380-5498.213

Copyright: (C) 2021 Loiselle MC, et al. This is an open-access article distributed under the terms of the Creative Commons Attribution License, which permits unrestricted use, distribution, and reproduction in any medium, provided the original author and source are credited.

\begin{abstract}
Existing decision support interventions regarding dialysis modality choice do not address important decisional needs for patients and their family.

Objective: To evaluate a nurse-led stage-based decision support intervention (SDESI) to promote informed values-based decision making.

Method: Guided by the Ottawa Decision Support Framework, a constructivist evaluation method with the participation of two nurses, six patients, and five family members was conducted.

Result: Participants revealed the structural characteristics of the SDESI that allowed continuity in decision making and contained specific helpful components supporting decision making process. Generally, participants' experiences were satisfactory and enlightening, supporting the SDESI as an acceptable, useful, and feasible program. However, the time to initiate the SDESI was suboptimal. More research is required to measure the effectiveness of SDESI.
\end{abstract}

Keywords: Advanced chronic kidney disease; Decision support interventions; Dialysis modality decision; Patient decision aid; Shared decision making; Decision coaching; Constructivist evaluation

\section{Decision Support Interventions and Dialysis Modality Decision}

International clinical practice guidelines recommend a shared decision making approach for patients with advanced chronic kidney disease (ACKD) when choosing hemodialysis (HD) or peritoneal dialysis (PD) because the available evidence does not identify the superiority of anyone modality in terms of chances of survival [13]. Prior to selection of a dialysis modality, patients usually attend predialysis education programs coordinated by nurses [4]. However, educational interventions appear rather ineffective in supporting this difficult decision [5] as patients continue to remain undecided [6]. The Ottawa Decision Support Framework (ODSF) is commonly used to identify patients' decisional needs, guide the design of decision support interventions (DESIs) tailored to needs such as indecision, and evaluate the quality of decisions made [7]. The framework asserts that DESIs such as patient decision aids and decision coaching help patients to make an informed choice that is based on the features of options that they value most. Patient decision aids (PDAs) are decision tools used to clarify the decision, inform patients about options and positive/negative outcomes and features, realign their expectations regarding likely outcomes, clarify their personal values to identify the most important outcomes and features, and guide them through deliberation and communication with health care professionals [7]. Decision coaching is a non-directive support provided by a trained health professional with the objectives of developing patients' skills to deliberate on the options, preparing them to discuss the decision with their physician and implementing the chosen option [8]. The benefit of DESIs has been well documented $[8,9]$.

A literature review over two decades identified seven published international studies on dialysis modality DESIs [4,10-15]. These studies demonstrated the feasibility and acceptability of DESIs in predialysis education and provided some evidence of their effectiveness. However, the studies did not describe their needs assessment findings, delineate the nursing role as a decision coach, nor describe the family members' perspectives. To expand our understanding of a DESI from the patient, family, and provider perspective we launched a three-phase study to 1) develop, 2) implement on a pilot basis, and 3) evaluate a nurse-led stage-based DESI comprising of four decision coaching sessions with a PDA guided by the ODSF [7] and the constructivist evaluation method [16]. The research protocol was approved by the ethical research committees of the institution and the university (No.14-05-42) [17]. 
This paper describes the third phase of the study, whose objective was to evaluate the experiences of the stage-based DESI (SDESI) among those who participated in its co-construction, namely, patients with ACKD, their spouses, and the nurses who provided the decision coaching. We have previously reported on phase 1 and $2[18,19]$.

\section{Methods}

We conducted a qualitative study involving multiple cases, using the constructivist evaluation method inspired by Guba EG, et al., [16], an evaluation process that facilitates meaningful collaboration with participants. We used a qualitative approach to obtain an in-depth understanding of the DESI context between the nurse, the patient, and his/her loved ones, and to enrich the decision coaching by making the nurses' work more visible. In this study, ACKD patients, family members, nurses, and the investigator were considered co-researchers in the research process. This method stresses the development of intersubjective understanding of the structure, process, and outcomes of an experience. The constructivist design required constant engagement by the researcher (MCL) who was familiar with the study environment (as a clinical nurse specialist for 12 years at the nephrology center) and had experience in conducting qualitative interviews.

\section{Setting}

We conducted the study at a French-Canadian teaching hospital predialysis outpatient clinic with a well-established multidisciplinary predialysis program. This clinic offers modalities such as in-center HD, satellite units' HD (include traditional and self-care), home HD, and home PD. These community-based satellite units are dialysis services for patients who are more independent and whose health conditions are generally stable. Other options are conservative management and a time-limited trial (TLT) as recommended by the Renal Physician Association [3]. Finally, patients are also informed about the option of pre-emptive living donation during pre-end-stage renal disease counseling.

Routine patient/family preparation for selection of a dialysis modality begins more formally when patients have stage 4 or 5 chronic kidney disease (glomerular filtration rate of less than $29 \mathrm{~mL} /$ min, or less than $15-10 \mathrm{~mL} / \mathrm{min}$ ) [20]. The nephrologist initiates the discussion of treatment options and then encourages the patient/ family to undertake the Group Information Sessions (GIS) so that at their next follow-up appointment, they can discuss the preferred option and plan for further action. The nurses' role in preparing the patient/family take place in three sessions. First, the nurse coordinator telephones the patient to schedule the GIS (five to six patients and their family members), ensuring that a family member accompanies the patient to the sessions. Second, the GIS are facilitated by the nurse coordinator, the in-center and home HD and PD nurse educators, as well as a nephrologist, renal dietician, pharmacist, and an expert dialysis patient. The educational curriculum includes components of successful CKD education programs described by Saggi SJ, et al., [21]. The options discussed are: 1) Conservative Management (no dialysis), 2) TLT, 3) PD home, 4) HD home, 5) In-center HD, and 6) Satellite unit's HD (include traditional and self-care). At the end of the GIS, participants are also given a free educational handbook for patients with kidney disease, published by the Kidney Foundation of Canada [22]. The third session is part of the regular medical follow-up at the clinic (every 1 to 3 months in stages 4 and 5 every until start of dialysis). The patient/family meets with the nurse coordinator, whose focus is on clinical observations and decision follow up, whereby patients/families ask questions and receive additional information.

\section{Case and participant selection}

In this study a case was defined as a nurse who applied the SDESI and the patients/families who received it. The nurses were selfselected via convenience sampling, as they had expressed an interest in participating in the study as co-researchers and had satisfied the research criteria, which stipulated at least 3 months of experience in a predialysis clinic and the completion of training in decision coaching (phase 1). To obtain maximum variation, the level of expertise in preparing patient to choose a type of dialysis, either expert or novice was considered.

Intentional sampling was performed to recruit patients and their families. In this study, the term "family" referred to any person(s) who played a significant role in an individual's life [23]. Patient selection was based on three sociodemographic characteristics that influence decisions [24], namely sex, age, and social support (living alone vs living with family). Considering all possible combinations of these characteristics, the inclusion of eight patients (with their families) was required.

Patients' inclusion criteria were as follows: stage 4 or 5 ACKD (without dialysis), stable condition, eligibility for all dialysis modalities at the time of referral to the GIS, ability to choose a dialysis modality, and ability to communicate in French. Patients were excluded if they required urgent dialysis and if they had cognitive impairment. The participants fulfilled all criteria. Recruitment was conducted in three spells between November 2011 and May 2013.

The total sample reports the experience of the SDESI as lived by the two nurses and six families: the nurse coordinator with four families and the PD nurse with two families. In case one, the nurse coordinator had 18 years of experience and acted has a co-researcher in the development of the intervention (SDESI) during phase 1. The other was the PD nurse who assisted the nurse coordinator occasionally. She had less than 1-year experience in preparing patients for the selection of a dialysis modality. They were both trained at the university level and in family nursing. The characteristics of patients and families for each nurse will be discussed in the result section.

\section{Intervention}

The development of the nurse-led SDESI has been described previously $[18,19]$. In brief, phase 1 consisted of developing a PDA to prepare patients for decision making during and following the GIS, and a decision-coaching skill building workshop to train the nurses in providing decision support prior to initiation of the SDESI.

Regarding the PDA, we worked with patients and practitioners to develop and alpha test a print version according to standardized ODSF methods [25] that also meet international standards [26]. The content was derived from an evidence review of key benefits, harms, and side effects of each option, a systematic overview of factors influencing the choice of a dialysis modality, and a decisional needs assessment. We trained expert dialysis patients to use the PDA in the GIS in guiding patients to clarify the features of options that they valued most.

The decision coaching training was informed by the ODSF-based needs assessment which revealed the patients' evolving decisional needs in five stages of the decision making journey (Box 1), and also uncovered additional patients' and families' decisional needs such as denial, anxiety, fear, and lack of receptivity to information that significantly hampered progress in the stages of decision making [18]. Using this five- 5 stage journey, we adapted the two routine nurse-led sessions (initial telephone call, GIS) and added two new individual decision coaching sessions with the patient/family before and after 
Box 1: The Evolving Decisional Needs through the Decision-Making Journey.

Phase 1: Progress toward acceptance of dialysis and become receptive to information.

Phase 2: Receiving information and become informed, reassured, and able to deliberate.

Phase 3: Take some time for personal reflection and become mobilized to communicate one's preferred option.

Phase 4: Seek opinion and support of others. Become confident in one's preferred option or delegate the decision.

Phase 5: Re-evaluate one's choice. If satisfied status quo and if not reevaluate.

Note: Full description of the five-stage journey can be found in Loiselle et al., [18]. In each phase, patients engage in one or more cognitive, affective, or social activities before moving on to the next phase. This pathway is not linear, and the patient may move back and forth between phases.

the GIS. The free educational handbook was now given before the GIS by the nephrologist when he advised the patient/family of the need for dialysis to provide adequate educational material while waiting to attend the GIS.

The elements of decision coaching training to address decisional needs were based on the model of Stacey D, et al., [27] that uses the ODSF. To address newly identified needs, we used the model of Duhamel F [23] to encourage the participation of the families in decision making and facilitate the patient's path to dialysis acceptance. The model of Leventhal $\mathrm{H}$, et al., [28] was used to help participants to express their perceptions of the disease and treatment via the Brief Illness Perception Questionnaire [29], as dialysis carries negative connotations that affect the decision-making process [19].

To facilitate implementation in practice, we worked with nurses to develop a decision-coaching guide (session-by-session) based on Decision Support Analysis Tool [30]. In phase 2, the SDESI was piloted in current practice using an educational coaching model [31].

The SDESI was conducted by the nurse coordinator and PD nurses who had been trained in decision coaching. The objectives of the SDESI nursing actions are summarized in table 1. To structure their SDESI, they used the decision-coaching guide to conduct the four sessions delivered via: $1^{\text {st }}$ Telephone call (10-15 minutes); $2^{\text {nd }}$ an individual meeting less than 2 weeks before GIS (45 minutes); $3^{\text {rd }}$ During the GIS, and $4^{\text {th }}$ an individual meeting less than two weeks after the GIS (45-65 minutes).

\section{Data collection}

Data were obtained from different sources. The first author (MCL) conducted all the semi-structured initial interviews (60-90 minutes) and validation interviews (20-30 minutes). Validation interviews, conducted with participants to confirm the interpretations of their experiences, consisted of questions to identify new leads, highlight contradictions between the opinions, and reach consensus [16]. Nurses' interviews $(\mathrm{n}=2+2$ for validation interviews) took place in their office at the predialysis clinic after sessions 2 and 4 . Patient/family interviews $(\mathrm{n}=3+2$ validation interviews) were held at their homes or at the clinic, as per the participants' choice. They were conducted soon after decision-coaching session $2(<1$ day, T1), coaching session 4 ( $<3$ days, T2), and for the patient, after the regular medical visit to
Table 1: Characteristics of patients and families.

\begin{tabular}{|c|c|c|c|}
\hline Patients/families & Sex & $\begin{array}{c}\text { Age } \\
\text { (y) }\end{array}$ & $\begin{array}{c}\text { Social Support } \\
\text { (living alone or with family) }\end{array}$ \\
\hline \multicolumn{4}{|l|}{$\begin{array}{l}\text { Case 1: Nurse coordinator and } \\
\text { her four patients and families }\end{array}$} \\
\hline $\begin{array}{l}\text { Patient } 1 \text { (Women)/Family } 1 \\
\text { (male spouse) }\end{array}$ & $\mathrm{F}$ & 63 & Lives with spouse \\
\hline $\begin{array}{l}\text { Patient } 2 \text { (Men)/Family } 2 \\
\text { (female spouse) }\end{array}$ & M & 57 & Lives with spouse \\
\hline $\begin{array}{l}\text { Patient } 3 \text { (Women)/Family } 3 \\
\text { (daughter) }\end{array}$ & $\mathrm{F}$ & 72 & $\begin{array}{c}\text { Widow, lives at her } \\
\text { daughter's house with her } \\
\text { family }\end{array}$ \\
\hline Patient 6 (Women) & $\mathrm{F}$ & 65 & Divorced, lives alone \\
\hline \multicolumn{4}{|l|}{$\begin{array}{l}\text { Case 2: PD nurse and her two } \\
\text { patients and families }\end{array}$} \\
\hline $\begin{array}{l}\text { Patient } 4 \text { (women)/Family } 4 \\
\text { (Child) }\end{array}$ & $\mathrm{F}$ & 80 & Widow, lives alone \\
\hline $\begin{array}{l}\text { Patient } 5 \text { (Men)/Family } 5 \\
\text { (female spouse) }\end{array}$ & M & 73 & Lives with spouse \\
\hline
\end{tabular}

the nephrologist (T3). The interview guides were designed to capture the evolution of the SDESI according to three major components. A sociodemographic questionnaire was included to demonstrate the diversity of the sample. In addition to those data, MCL kept a research journal [16].

\section{Conduct of the study}

The study involved concurrent data collection and analysis, in accordance with the method using the hermeneutic dialectic circle described by Guba EG, et al., [16]. More specifically, each case was developed as a spiral, during which participants could react to prior interpretations, except for the first interview. Data collection followed a parallel path in both cases.

Nurse: In the first interview, the nurse provided sociodemographic data and described her experience of the SDESI delivered in the first and second decision-coaching sessions. Then narratives were constructed. In the second interview, the nurse described her experience of the SDESI in the fourth decision-coaching session and validated the narratives constructed for the first interview. The third interview was conducted via a telephone call. It served to validate the narrative constructed for the second interview.

Patients/families: In the first interview, the interviewees (alone, or accompanied by the family) described their SDESI experiences in the first and second decision-coaching sessions. They also provided sociodemographic data, and narratives were constructed. In the second interview, the interviewees described their experiences of the SDESI in the third and fourth decision-coaching sessions. They also validated the narratives constructed for the first interview. In the third interview, the interviewees described their experiences during the consultation with the nephrologist; they also validated the narratives constructed for the second interview. The fourth interview was conducted via telephone. It served to validate the narrative constructed for the third interview.

Upon completion of the interviews, the narratives of SDESI of the nurse, patients, and families on the decision-coaching sessions 1,2 , and 4 were brought together to produce a synthesis called the "combined narrative." In a fifth_interview for the patient's family, and a fourth for the nurse, the interviewees validated these "combined 
narratives" for each triad or dyad nurse- patient/family, integrating a consultation with the nephrologist. A synthesis was then done for each case. In view of the similarity between the syntheses of the two cases, they were combined to form a single summary, which was analyzed to construct the results of the study.

\section{Data analysis}

We analysed recorded and transcribed interviews using Word 2010 functions, with a conventional hermeneutic technique and a dialectic process of comparison, contrasting with frequent confirmation [32]. The analysis included a cyclical and reflexive process. The researcher's introspection and interpretations were validated during succeeding interviews with participants, and during regular debriefings with a coauthor. The verbatim transcripts were read several times to establish a global understanding of the content. Our codification was inductivedeductive, followed by classification related to the similarity/difference rule, which was based on Donabedian A [33] classic paradigm for assessing care quality, organized in three-components. They were structure (duration, length, and timing of the sessions), process (preparation and intervention), and experiment outcomes (acceptability, usefulness, feasibility, and satisfaction). This paradigm was adapted to the context of the research project and was used to provide a structure for drafting narratives, "combined narratives", and summaries. All interpretations (narratives, "combined narratives", and summaries) were reviewed by the coauthors for peer debriefing.

\section{Procedure and ethics}

The two nurses who agreed to participate in the study signed consent forms. Then they identified patients who met the selection criteria and approached them and their families when they attended the predialysis clinic for the second decision-coaching session. All patients and families who were approached agreed to participate and signed the informed consent form.

\section{Results}

\section{Case and participants' characteristics}

Table 2 presents the characteristics of the patients and families for each case. They were very diverse and reflected the characteristics (sex, age, and support [living alone $v s$ living with family]) that exerted a strong influence on decision making. However, within the allotted time, we were unable to recruit men of any age who lived alone.

The negotiated participants' experiences of the SDESI were presented in terms of the predetermined category of Donabedian's structure, process, and outcomes. Under each category, different themes emerged from the interviews.

\section{SDESI structure: adequate but timing for session 1 needs to be improved}

The theme that emerged regarding the structure of the SDESI was that of adequate duration and the need for improved timing for the first session. The participants considered the duration of the sessions as adequate. Both nurses judged the length of the session as appropriate, with limited risks of information overload. One patient felt that session 3 was overextended because some participants repeatedly interrupted the nurses (predialysis, hemodialysis, and peritoneal dialysis nurse) with questions. According to nurse 2, this behavior was probably related to the fact that some participants in that session "were less prepared" as they were not part of the experiment.
The intervals between sessions were viewed as the "optimal normal continuum" (Nurse 2) that fostered trust, continuity between the sessions, and integration of information of patients and families. In terms of timing of the first session, all participants believed that this session should be provided relatively soon (within 2 months) after the nephrologist has advised the patient to attend the GIS, to prepare for the selection of a dialysis modality. Some patients and families noted that they had waited for " 6 to 12 months" between being notified of the imminent need for dialysis and being referred to the nurse for information and decision support. The nurses added that delays could occur because of their workloads (notes from the journal). After a certain period of delay, some patients said that they lost interest and found themselves "falling into a void" (Patient 2). They also felt "disarmed" when facing the unsupported scaremongering by some professionals (Patient 3-Family 3). In contrast, another participant said, "the second session provided the information that we needed" (Family 2: spouse).

\section{SDESI process: support for decision making}

Regarding the process, two themes were captured from the participant's experience of the SDESI (preparation for DESIs and interventions to support the decision making process). Participants highlighted the importance of preparing for each decision-coaching session. Nurses could do this by reviewing the decision-coaching guide, while patients and families could read the free information handbook or PDA. The nurses emphasized the importance of customizing the decision coaching. "I did it [provided four decision-coaching sessions] with four patients, and I think that each time was a bit different, as you have to adapt to each patient" (Nurse coordinator).

As to interventions to support the decision making process, participants approved nurse's actions of the SDESI (Table 2) and highlighted the way in which a trusting relationship, on an equal basis with the nurse, enabled the patient to participate in the decision. "You don't feel forced into anything; you can choose for yourself" (Patient 5). Table 3 presents some examples of quotes of participant's salient nurses' actions according to their objectives.

When asked to identify the most helpful intervention, the vast majority of participants mentioned the SDESI ("it's the whole thing that's helpful [PD Nurse])" and expert dialysis patients' testimonies ("Honestly, that's very good" [Patient 4]).

\section{SDESI outcomes: acceptable, useful, feasible, and satisfacto- ry to support decision making}

In terms of outcomes, three major themes emerged from the interview data: 1) acceptability and usefulness, 2) feasibility to support decision making, and 3) satisfaction. The opportunity to experience the SDESI allowed participants to evaluate its acceptability. All participants believed that the components included in each decision-coaching session were relevant to patients and families. They mentioned that the information was sufficient in quantity, "clear," presented in "simple" terms, and balanced (decision-coaching session and PDA) "if an equal amount of time is spent on each option" (Patient 1). They added that the information was easier to absorb when it was presented "in a concrete way" (referring to a visit to the hemodialysis center and the demonstration of the fluid exchange during peritoneal dialysis). The PDA helped other family members who did not attend the sessions to understand chronic kidney disease and their dialysis options.

Participants felt that the SDESI was useful in choosing a dialysis modality. Patient 2 mentioned: 
Table 2: Objectives of nursing actions in the SDESI.

1. Establish/maintain trust: reassure and support.

2. Assess/address patient-family journey toward acceptance of end stage of CKD and need for dialysis based on Duhamel's family nursing interventions (2015).

a. Determine the family structure (genogram) and acknowledge family resources.

b. Facilitate emotional expression and demonstrate empathy. Tools were used: Visual analogue scale on emotion embedded in the PDA adapted from Williams VSL, et al., [34]; Brief illness perception questionnaire adapted from Broadent et al. (2006); Mini-Geriatric depression scale of Clément JP, et al., [35].

c. Reframe previous experiences of dialysis.

d. Highlight the patient/family's strengths.

e. Provide comfort and offer hope.

3. Clarify the dialysis modality decision in assessing the patient's interest in life and goals and explore whether conservative management is an option.

4. Facilitate receptiveness to information.

a. Provide information on blood/urine test (compare patient's results to results from previous tests or teach reference value to help patient/family understand the disease.

b. Teach stages of CKD and clinical action plan to each stage, using a chart.

c. Encourage attendance at GIS.

5. Assess/Address knowledge \& expectations according to session topics.

a. Provide written educational and decision support material in a timely manner.

b. Provide experiential information delivered by trained expert dialysis patients.

c. Provide information to help families to determine their role in supporting the decision.

6. Clarify values (personal importance of the features of each dialysis option with PDA).

7. Assess/address support \& resources needs: social and instrumental support, social pressure with PDA.

8. Monitor/facilitate progress in decision making stage and patient's preferred treatment option guided by the PDA.

a. Improving skills in communicating preference by acknowledging the patient's skills in making the most appropriate choice.

9. Screen for unresolved decisional needs guided by PDA.

10. Plan follow-up (next step) guided by PDA.

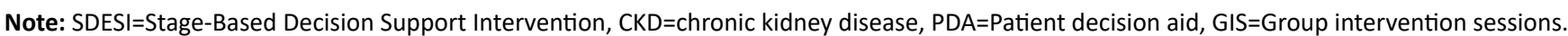

"It is truly useful. Without these meetings [decision-coaching sessions], I would still be wondering about what to do, not about whether I want dialysis or not, but more about what will happen, how it will go... and which type of dialysis... I didn't know that: I thought there was only one form [hemodialysis]" (Patient 2).

At the end of the decision-coaching session 4, all patients had identified their preferred dialysis modality (with an equal division between $\mathrm{HD}$ and PD). They stated that they had received sufficient information to decide, and were convinced that their decisions reflected the most appropriate options for them. All patients could communicate their choices to their nephrologists. In addition, patients/ families stated that the SDESI affected their emotions by helping them to proceed positively toward accepting dialysis. As explained by one patient:

"It helped me a lot to decide, because I used to be unsure and closed-minded, but the way she explained it to me, I was able to think positively about it, and then I was able to say," "Look, I've reached the point where I have to [have dialysis], and it [peritoneal dialysis] isn't so bad, so let's do it" (Patient 5).

Families stated that the information-gathering stage allowed them to deliberate on options among themselves. They learned that their role in helping their loved ones to make a choice was not to influence them to choose a specific dialysis modality, since it would have been only "a source of conflict in the couple" and a "waste of energy" (Family 2, spouse). Another family reported feeling "readier" to meet the doctor to talk about options (Family 1, spouse).

Participants generally described their experience of the SDESI in very positive terms. Patients/families emphasized their general appreciation, with one of them stating, "I liked everything." Some even described it as "perfect." Others considered the SDESI "enlightening," as it "eliminated" false beliefs and fears, improving their "well-being" (Patient 3). Patients and families also appreciated the fact that the process was structured, progressive, and supported by the family. As explained by Patient 6, "We felt well guided; we started here, then we had this, and then we moved on to there." Two patients stated that they were more inclined to discuss their decisions with their nephrologists, and one explained that she could "think more critically when discussing [my decision] with [my] nephrologist, because [I] was able to ask the right questions" (Patient 1 ).

Participants agreed on the feasibility of the SDESI in practice given that the amount of time required was considered more than reasonable. In addition, it was possible to ask patients and their families to participate in the study, even if they were experiencing a crisis; none of the recruited patients and their families refused the invitation.

According to the nurses, the SDESI brought them "great satisfaction." They found the experience rewarding because it gave their work meaning. One of the nurses stated, "For me, doing it this way is, wow... Yes, of course, I'm doing better coaching this way, that's for sure" (Nurse 
Table 3: Examples of participants' salient nurse's actions of the SDESI aligned with their objectives.

\begin{tabular}{|c|c|}
\hline Nurse's actions & Quotes of participants \\
\hline \multicolumn{2}{|c|}{ Assess/address patient-family journey toward acceptance of end stage of CKD and need for dialysis. } \\
\hline $\begin{array}{l}\text { Determine the family structure (genogram) and acknowledge family } \\
\text { resources. }\end{array}$ & $\begin{array}{l}\text { "She (nurse) asked me questions about my family, my interest in life, my living } \\
\text { conditions and I think it is important and it gives us confidence" (Patient 4). }\end{array}$ \\
\hline Facilitate emotional expression and demonstrate empathy & $\begin{array}{l}\text { "I told them that I understand their situation, that it's sad and overwhelming, } \\
\text { and then I got the feeling that it calmed them down" (Nurse coordinator). }\end{array}$ \\
\hline Provide comfort and offer hope. & $\begin{array}{l}\text { Patients/families needed to be "comforted" and offered "hope" to overcome } \\
\text { restrictive beliefs about dialysis and believe in their ability to communicate } \\
\text { their choices to their nephrologists. (Patient and Family 3). }\end{array}$ \\
\hline \multicolumn{2}{|c|}{ Clarify the dialysis modality decision in assessing the patient's interest in life and goals and explore whether conservative management is an option. } \\
\hline Clarify the dialysis decision. & "Very important to ask, 'Do I want dialysis or not?” (Patient 6). \\
\hline \multicolumn{2}{|l|}{ Facilitate receptiveness to information. } \\
\hline $\begin{array}{l}\text { Teach stages of CKD and clinical action plan to each stage, using a } \\
\text { chart. }\end{array}$ & $\begin{array}{l}\text { "When she presented the different stages of the disease on the chart", } \\
\text { especially when she showed me where I was. I realized I didn't have much left } \\
\text { [renal function]. At that point, I wanted more information." }\end{array}$ \\
\hline $\begin{array}{l}\text { Provide information on the options available to patients and their } \\
\text { families before attending to GIS to reduce overload of information. }\end{array}$ & $\begin{array}{l}\text { This information prepares them [patients/families] to take in a "big chunk" of } \\
\text { the GIS (Session 3) (Family 3). }\end{array}$ \\
\hline \multicolumn{2}{|l|}{ Assess/Address knowledge \& expectations according to session topics. } \\
\hline Provide experiential information delivered by expert dialysis patients. & $\begin{array}{l}\text { Because the nurse's technical description is fine and all that, but that woman, } \\
\text { she's been living with it: how she works it out at home, how she manages to } \\
\text { travel, and so on" (Family 1). }\end{array}$ \\
\hline $\begin{array}{l}\text { Provide written education and decision support materials in a timely } \\
\text { manner. }\end{array}$ & $\begin{array}{l}\text { Patients felt that handing out the PDA sent the message that "a decision needs } \\
\text { to be taken, and you can't postpone indefinitely" (Patient 2). }\end{array}$ \\
\hline $\begin{array}{l}\text { Provide information to help families to determine their role in } \\
\text { supporting the decision. }\end{array}$ & $\begin{array}{l}\text { "This really opened my eyes, because I nagged him too much before the } \\
\text { training. But now, I believe he is supported by the health professionals, and } \\
\text { my personal support consists of being there for him and accompanying him" } \\
\text { (Family 2). }\end{array}$ \\
\hline \multicolumn{2}{|c|}{ Clarify values (personal importance of the features of each dialysis option with PDA). } \\
\hline $\begin{array}{l}\text { Conduct a thorough review of the score of each value statement with } \\
\text { patient/family. }\end{array}$ & $\begin{array}{l}\text { "At each question [statement in the PDA], she would ask me what I truly } \\
\text { thought. She would read it, and then she would ask me 'Why did you give it } \\
\text { that score?' I would tell her why, and then she would explain things to me. She } \\
\text { was making sure that this represented my choice" (Patient 5). }\end{array}$ \\
\hline \multicolumn{2}{|c|}{ Monitor/facilitate progress in decision making stage and patient's preferred treatment option guided by the PDA. } \\
\hline $\begin{array}{l}\text { Improving skills in communicating preference by acknowledging the } \\
\text { patient's skills in making the most appropriate choice. }\end{array}$ & $\begin{array}{l}\text { "When I told her: "I'm glad you made a choice and that you feel sure about } \\
\text { your choice; it makes me happy...There, she smiled at me. I think she was } \\
\text { happy; it helped her to know that I was happy that she'd made her choice..." } \\
\text { (Nurse coordinator } 1 \text { ). }\end{array}$ \\
\hline
\end{tabular}

Note: SDESI=Stage-Based Decision Support Intervention, CKD=chronic kidney disease, PDA=Patient decision aid

coordinator). The SDESI provided them with "a more systematic and better-structured approach" to help patients; the decision-coaching guide supported the coaching process. One nurse also discovered that the reciprocity she experienced in the coaching relationship helped her to improve her skills: "Yes, she [Patient 6] helped me. I helped her, but she also helped me in all that" (Nurse coordinator). The nurses also mentioned that they appreciated the fact that the researcher had accompanied them through the implementation of the SDESI in their practice.

\section{Discussion}

To our knowledge, this was the first study to develop, implement, and evaluate a SDESI using a constructivist evaluation method [16]. This method facilitated the identification of the subtleties of the SDESI in terms of the structure, process, and outcomes, thereby elucidating how the nurse carried out the DESIs, revealing her critical role in preparing the patients and their families for the choice of dialysis modality. In this study, we were able to evaluate the SDESI from the families' perspective which is an understudied area of inquiry and a matter of importance considering the critical role played by them [36]. Generally, participants' experiences were satisfactory and enlightening, supporting the SDESI as an acceptable, useful, and feasible program.

The study yielded interesting results regarding the structure of the intervention. Using a map of a patients' evolving needs in their decision making journey, participants favored a stage-based intervention that included personal preparatory activities and decision-coaching sessions, before, during, and after the group educational process, with short intervals between decision-coaching sessions. Our results converge with those obtained by Belkora J, et al., [37], who showed that patients with cancer who benefitted from decision coaching by medical students at different times in the continuum of oncology care, experienced a significantly improved quality of the decision making process. These findings advocate the need for an ongoing intervention to support decision making in the context of chronic disease. In terms of the short interval between decision-coaching sessions, our results are consistent with those of van Roosmalen MS, et al., [38] showing 
that the intensity of decision coaching ensures continuity and longterm well-being. These findings are important because if applied to the conservative kidney management (CKM) pathway, it could help care providers to support the decision to initiate dialysis or not at critical moments during the patient's kidney disease. As argued by Davison $\mathrm{SN}$, et al., [39] existing models of CMK have been developed but patients still have unmet needs.

Timing to initiate the SDESI was an issue. Participants highlighted the importance of initiating the SDESI early, once the nephrologist informs patients that they require dialysis, to ensure emotional support in choosing a dialysis modality. Moreover, patients and families emphasized the consequences of postponing decision support. This suggests that referral for preparation in choosing a dialysis modality goes beyond a specific stage (such as stage 4), and discussion over the referral process between nephrologists and nurses would be advisable. Our results are directly in line with those of who suggested that early implementation increases the acceptability of interventions [40]. These findings highlight the importance of the nurse decision coach's role in improving decision making and support the authors who argue that PDAs alone cannot address continuity [41].

With respect to the process, the participants emphasized that the nurses' actions helped patients and families choose a dialysis modality. The results showed that decision coaching interventions, based on the ODSF, supported the decision making process, which is consistent with the findings of Bissonnette J, et al., [10] and Feenstra B, et al., [40]. In addition, participants understood that the PDA is part of a continuum of DESI, which suggests that a PDA without decision coaching could be insufficient to aid patients in the selection of a dialysis modality [10].

Regarding the Duhamel F family intervention model, nurses said that its tools allowed them to quickly assess decisional needs to customize their decision coaching. The provision of family nursing interventions helped patients and their families to improve their skills in overcoming challenges, supported their participation in decision making, and assisted families to identify their own means of alleviating the physical and emotional symptoms of patients' conditions, as proposed by Duhamel F, et al., [23]. The participants in this study also stressed nurses' empathy as being helpful. Our results on shared decision making resonate with those of authors who strongly believe that empathic conversations build trust with patients and their families and lead the discussion more carefully toward deliberation of options [42]. Empathy requires the ability to notice patient verbal and non-verbal cues and respond to these accurately, when he is invited into the deliberative process [43]. In family nursing actions, nurses could discuss sensitive topics (such as the decision to initiate dialysis, acceptance of dialysis, and social pressure to decide), even in the presence of the family. This was an important step because professionals (nephrologists and nurses) have always struggled to talk about difficult issues $[3,37,44]$. These results are also important because they support the Renal Physician Association guideline (2010) which recommends discussing the decision to initiate dialysis, addressing preoccupations and fears, focusing on the treatment plan, respectful of the patient/family needs and goals, and explore end-of-life issues.

Findings suggest that interventions based on the model by Leventhal $\mathrm{H}$, et al., [28] supported the patients and families in increasing their receptivity to information and expression of emotions using the Brief Illness Perception Questionnaire [29]. However, in our cohort, it was used only in one patient who experienced very strong emotions. To enhance the SDESI, additional studies are required to examine the actual impact of these interventions on the quality of decisions, and on patients' satisfaction with the process.
Our findings reveal that expert dialysis patients are assets in helping patients and their families choose a dialysis modality, and their training is crucial. These results provide additional support for studies that have shown that expert dialysis patients are invaluable in helping to choose a dialysis modality [11]. Similar to the patient-partner approach, expert patients increase patients' sense of self-efficacy in communicating with professionals and in participating in decision making [45].

Concerning the outcomes, our results showed the acceptability and the usefulness of DESIs (decision coaching+PDA) in choosing a type of dialysis in the context of ACKD; these observations are consistent with the finding of Bissonnette J, et al., [10]. They are also similar to that of other studies, in which the use of a PDA was embedded in the pre-dialysis education program [11-13,18]. Moreover, all patients/ families were able to communicate their choice to their nephrologist. These findings are in line with the coaching model that we used [27], which endeavor to increase patients' confidence in communicating their choices to health care professionals.

In this study, the overall satisfaction with the SDESI was high. Interviewed patients and families emphasized that the SDESI made them feel good and provided comfort. They appreciated the structured and reflective coaching provided at each step of the decision making process, similar to the decision coaching model of Stacey D, et al., [27].

The nurse participants stated that the application of the SDESI increased the value of their role in preparing patients and their families for the selection of a dialysis modality. This result is concordant with those of Murray AM, et al., [46] which showed that nurses had more positive perceptions of the decision support intervention after decision-coaching training.

The main strength of our study was the use of a constructivist evaluation method, proposed by Guba EG, et al., [16], considering the existing gap in knowledge. Adopting this method, we could pool the perspectives of the people involved in choosing a modality of dialysis, and thus co-construct an SDESI that is applicable in the predialysis continuum of care. We also believe that the collaboration with clinical nurses has allowed the integration of the SDESI into practice. This is important because, as noted by Winterbottom AE, et al., and Elwyn G, et al., [15,47], although there are effective PDA to support the decision, their integration into the practice remains difficult; these are hardly or never used in practice. As noted by Young L [48], participatory research is a good strategy for nursing research as it generates knowledge that can inform practice. We also believed that the harmonization of the SDESI by the training for nurses and dialysis patients using the "five-stage journey", was the building block of this study and the stepping-stone to success with the intervention. Other strengths of this qualitative evaluation lie in the use of trustworthiness criteria proposed by Guba EG, et al., [16]. To ensure credibility of the data, different techniques (member checking, peer checking, and debriefing of emerging categories and themes with the coauthors) were used. To improve the confirmability and dependability of this study, we maintained a detailed audit trail of field notes in our research journal, audiotaped recordings, data analysis records, and product synthesis. In addition, to achieve confirmability, we ensured that results could be traced back to their sources and to the logic used to combine interpretations into a coherent whole. Finally, to enhance transferability of this study, we included a detailed description of the study's setting, participants, and data collection process.

The study was subject to some limitations. First, the findings are limited to the perspective of the patients and families attending 
the pre-dialysis clinic where the study took place. The clinic valued integrating research, and evidence-based nursing. Second, case participants lacked complete diversity because we could not find a man living alone. Third, the interviews were conducted with the patient and family together, aiming for a consensus [16]. Therefore, it is possible that valuable information may not have been expressed, owing to the presence of the other. Finally, evaluation was limited to acceptability and feasibility of the intervention. The effectiveness of the SDESI decision on outcomes will require further research.

Regarding subsequent use of the SDESI after the study completion, the fourth decision coaching session is now routine. The nurse coordinator schedules an appointment with the participants, reminding them to bring their PDA with the completed values clarification exercise. As to the second decision coaching session, it is not completely implemented as discussions to improve the referral system to the pre-dialysis program (as soon as the nephrologist introduces dialysis options) are underway.

This study contributed to an innovative method for designing and implementing a stage-based SDESI in shared decision making and provided some useful guidance in their development. It also provided nursing practice with a better description of its specific role, responsibilities, and contributions to shared decision making, which remains insufficiently articulated [49]. Based on the ODSF, the next step would be to evaluate the acceptability of the SDESI in a more diverse group of patients, as well as the effects on informed, values-based decisions. With the addition of Duhamel's family nursing interventions and Leventhal's model, our results have enriched DESIs by helping patients and their families move toward accepting dialysis, thereby increasing their receptivity for DESIs. This study offers an SDESI that is described in sufficient detail to allow its application in other contexts. Finally, this study provided a foundation for future research.

\section{Acknowledgments}

This study was supported by a doctoral training grant from the Interuniversity Nursing Intervention Research Group (GRIISIQ) in Quebec, the Ministry of Education, Leisure and Sports of Quebec province, and the Research funds from the Sherbrooke University and the GRAPPE of the Charles LeMoyne university-affiliated hospital in Quebec province.

\section{Conflict of Interests}

None.

\section{References}

1. National Institute for Health and Clinical Excellence (2011) Kidney disease: peritoneal dialysis in the treatment of stage 5 chronic kidney disease.

2. National Kidney Foundation (2015) KDOQI clinical practice guideline for hemodialysis adequacy: 2015 update. Am J Kidney Dis 66: 884930 .

3. Renal Physicians Association (2000) Shared decision-making in the appropriate initiation of and withdrawal from dialysis. Renal Physician Association, United States.

4. Prieto-Velasco $M$, Quiros $P$, Remon $C$, Spanish Group for the Implementation of a Shared Decision Making Process for RRT Choice with Patient Decision Aid Tools, et al. (2015). The concordance between patients' renal replacement therapy choice and definitive modality: is it a utopia? PLOS ONE, 10: e0138811.
5. Van den Bosch J, Warren DS, Rutherford PA (2015) Review of predialysis education programs: a need for standardization. Patient Prefer Adherence 9: 1279-1291.

6. Maaroufi A, Fafin C, Mougel S, Favre G, Seitz-Polski B, et al. (2013) Patients' preferences regarding choice of end-stage renal disease treatment options. Am J Nephrol 37: 359-369.

7. Stacey D, Légaré F, Boland L, Lewis KB, Loiselle MC, et al. (2020) 20th Anniversary Ottawa Decision Support Framework: Part 3 Overview of Systematic Reviews and Updated Framework. Med Decis Making 40: $379-398$.

8. Stacey D, Kryworuchko J, Bennett C, Murray MA, Mullan S, et al. (2012) Decision coaching to prepare patients for making health decisions: A systematic review of decision coaching in trials of patient decision AIDS. Med Decis Making 32: E22-E33.

9. Stacey D, Légaré F, Lewis K, Barry MJ, Bennett CL, et al. (2017) Decision aids for people facing health treatment or screening decisions. Cochrane Database Syst Rev 4: CD001431.

10. Bissonnette J, Murray MA, Graham J (2014) Shared end-stage renal patient's decision making (SHERPA-DM) project. Submitted to Ontario Renal Network: Innovation proposal 2013-2014.

11. Finderup J, Jensen JKD, Lomborg K (2018) Developing and pilot testing a shared decision-making intervention for dialysis choice $J$ Ren Care.

12. Finderup J, Lomborg K, Jensen JD, Stacey D (2020) Choice of dialysis modality: patients' experiences and quality of decision after shared decision-making. BMC Nephrol 21: 330.

13. Fortnum D, Grennan K, Smolonogov T (2015) End-stage kidney disease patient evaluation of the Australian 'My Kidneys, My Choice' decision aid. Clin Kidney J 8: 469-475.

14. Princhard A, Thomas N (2013) The option grid: A shared decision making tool for renal patients. J Ren Nurs 5: 6-11.

15. Winterbottom AE, Gavaruzzi T, Mooney A, Wilkie M, Davies SJ, et al. (2016) Patient acceptability of the Yorkshire Dialysis Decision Aid (YoDDA) booklet: A prospective non-randomized comparison study across 6 predialysis services. Perit Dial Int 36: 374-381.

16. Guba EG, Lincoln YS (1989) Fourth generation evaluation. Sage Publications, California.

17. Loiselle MC, O'Connor A, Michaud C (2011) Developing a decision support intervention regarding choice of dialysis modality. CANNT J 21: 13-18.

18. Loiselle MC, O'Connor A, Michaud C (2016) Decisional Needs Assessment to Help Patients with Advanced Chronic Kidney Disease Make Better Dialysis Choices. Nephrol Nurs J 43: 463-493.

19. Loiselle MC (2017) Design, implementation, and evaluation of a decision support intervention to help choosing a type of dialysis for people with advanced chronic kidney disease and their families. [Conception, implantation et évaluation d'une intervention de soutien à la décision pour aider le choix d'un type de dialyse pour des personnes atteintes d'une maladie rénale chronique avancée et leur famille]. University of Sherbrooke, Longueuil, Québec.

20. McFarlane P, Gilbert RE, MacCallum L, Senior P, Canadian Diabetes Association Clinical Practice Guidelines Expert Committee, et al. (2013) Chronic kidney disease in diabetes. Can J Diabetes 37: S129-S136.

21. Saggi SJ, Allon M, Bernardini J, Kalantar-Zadeh K, Shaffer R, et al. (2012) Considerations in the optimal preparation of patients for dialysis. Nat Rev Nephrol 8: 381-389. 
22. Kidney Foundation of Canada (2015) Book two. Living with kidney failure, $5^{\text {th }}$ edition, Canada.

23. Duhamel F (eds) (2015) Families and health. A systemic approach in nursing care. [La santé et la famille. Une approche systémique en soins infirmiers] $3^{\text {rd }}$ edition, Montréal, Québec, Canada: Gaëtan Morin éditeur, Chenelière Éducation.

24. Harwood L, Clark AM (2014) Dialysis modality decision-making for older adults with chronic kidney disease. J Clin Nurs 23: 3378-3390.

25. Ottawa Hospital Research Institute (2015) Patient Decision Aids, Canada.

26. Elwyn G, O'Connor A, Stacey D, Volk R, Edwards A, et al. (2006) Developing a quality criteria framework for patient decision aids: Online international Delphi consensus process. BMJ 333: 417.

27. Stacey D, Murray MA, Légaré F, Dunn S, Menard P, et al. (2008) Decision coaching to support shared decision making: A framework, evidence, and implications for nursing practice, education, and policy. Worldviews Evid Based Nurs 5: 25-35.

28. Leventhal H, Nerenz DR, Steele DJ (1984) Illness representations and coping with health threats. In: Baum A, Taylor SE, Singer JE (eds) Handbook of Psychology and Health. Taylor \& Francis, United kingdom, 219-252.

29. Broadbent E, Petrie KJ, Main J, Weinman J (2006) The brief illness perception questionnaire. J Psychosom Res 60: 631-637.

30. Stacey D, Taljaard M, Drake ER, O'Connor AM (2008) Audit and feedback using the brief Decision Support Analysis Tool (DSAT-10) to evaluate nurse-standardized patient encounters. Patient Educ Couns 73: 519-525.

31. Rush DD, Shelden ML, Hanft BE (2003) Coaching families and colleagues: A process for collaboration in natural settings. Infants \& Young Children 16: 33-47.

32. Skrtic TM, Guba EG, Knowlton HE (1985) Interorganizational special education programming in rural areas: Technical report on the multisite naturalistic field study volumes I through IV. Washington, DC.

33. Donabedian A (1988) The quality of care. How can it be assessed? JAMA 260: 1743-1748.

34. Williams VSL, Morlock RJ, Feltneret D (2010) Psychometric evaluation of a visual analog scale for the assessment of anxiety. Health and Quality of Life Outcomes 8: 57.

35. Clément JP, Preux PM, Fontanier D, Léger JM (2001) Mini-GDS in elderly population administered by general practitioners. Encephale 27: 329-337.

36. Hawley ST, Morris AM (2017) Cultural challenges to engaging patients in shared decision making. Patient Educ Couns 100: 18-24.
37. Belkora J, Volz S, Loth M, Teng A, Zarin-Pass M, et al. (2015) Coaching patients in the use of decision and communication aids: RE-AIM evaluation of a patient support program. BMC Health Serv Res 15: 209.

38. van Roosmalen MS, Stalmeier PF, Verhoef LC, Hoekstra-Weebers JE, Oosterwijk JC, et al. (2004) Randomized trial of a shared decision making intervention consisting of trade-offs and individualized treatment information for BRCA1/2 mutation carriers. J Clin Oncol 22: 3293-3301.

39. Davison SN, Levin A, Moss AH, Jha V, Brown EA, et al. (2015) Executive summary of the KDIGO controversies conference on supportive care in chronic kidney disease: Developing a roadmap to improving quality care. Kidney Int 88: 447-459.

40. Feenstra B, Lawson ML, Harrison D, Boland L, Stacey D (2015) Decision coaching using the Ottawa family decision guide with parents and their children: A field testing study. BMC Med Inform Decis Mak 15.

41. Nolte E, McKee M (2008) Caring for people with chronic conditions: A health system perspective. Open University Press, England.

42. Serrano V, Rodriguez-Gutierrez R, Hargraves I, Gionfriddo MR, Tamhane S, et al. (2016) Shared decision making in the care of individuals with diabetes. Diabet Med 33: 742-751.

43. Montori V (2015) For empathic decision making.

44. Noble H, Brazil K, Burns A, Hallahan S, Normand C, et al. (2017) Clinician views of patient decisional conflict when deciding between dialysis and conservative management: Qualitative findings from the PAlliative Care in chronic Kidney diSease (PACKS) study. Palliat Med 31: 921-931.

45. Sheppard VB, Wallington SF, Willey SC, Hampton RM, Lucas W, et al. (2013) A peer-led decision support intervention improves decision outcomes in black women with breast cancer. J Cancer Educ 28: 262269

46. Murray AM, Stacey D, Wilson KG, O'Connor AM (2010) Skills training to support patients considering place of end-of-life care: $A$ randomized control trial. J Palliat Care 26: 112-121.

47. Elwyn G, Scholl I, Tietbohl C, Mann M, Edwards AGK, et al. (2013) "Many miles to go ...": a systematic review of the implementation of patient decision support interventions into routine clinical practice. BMC Med Inform Decis Mak 13 Suppl 2: S14.

48. Young $L$ (2006) Participatory action research (PAR): A research strategy for nursing? West J Nurs Res 28: 499-504.

49. Lewis BK, Stacey D, Squires JE, Carroll SL (2016) Shared DecisionMaking Models Acknowledging an Interprofessional Approach: A Theory Analysis to Inform Nursing Practice. Res Theory Nurs Pract 30: 26-43. 